\title{
PENGARUH HIPPOTHERAPY TERHADAP PENINGKATAN KONTROL POSTUR ANAK DENGAN KONDISI CEREBRAL PALSY SPASTIK DIPLEGI
}

\author{
Sari Triyulianti ${ }^{1)}$ \\ ${ }^{1)}$ Program Studi D-III Fisioterapi \\ Fakultas Kedokteran dan Ilmu Kesehatan \\ Universitas Abdurrab \\ Jl. Riau Ujung no. 73 Pekanbaru \\ Email : sari.tri.y@univrab.ac.id
}

\begin{abstract}
Background: Cerebral palsy (CP) refers to a group of disorders of the development of movement and posture that are attributed to a non-progressive lesion that occurs in the immature brain. Children with CP have various degrees of impairment of postural control which can limit physical activity and participation in daily life. Clinical observations have suggested that hippotherapy may be an effective strategy for habilitating postural control deficits in children with CP spastic diplegic. However, there is limited research to support this notion. This case study aimed to investigate the effects of hippotherapy on postural control in children with CP spastic diplegic. Methods: Single case study with pre and post test design of a girl with CP spastic diplegic aged 19 years. A hippotherapy protocol was performed for 45 minutes, twice a week, for 3 weeks. Each hippotherapy session consisted stretching, strengthening, and balance activities. Posture Assesment Scale, a criterion-referenced observational measure designed to measure change in the postural control in children with CP spastic diplegic, was chosen as the assessment tool. Results: Upon completion of the 3-week intervention, there was improvement scores in posture assesment scale. The results showed that there was difference score of posture assesment scale on pre hippotherapy $\left(T_{0}=7\right)$ and post hippotherapy $\left(T_{6}=9\right)$. Conclusion: The results of this study demonstrate that hippotherapy can improve postural control in children with CP spastic diplegic.
\end{abstract}

Keywords: hippotherapy, postural control, cerebral palsy spastic diplegic

\begin{abstract}
ABSTRAK
Latar Belakang: Cerebral Palsy (CP) merupakan suatu kelompok gangguan perkembangan gerak dan postur yang diakibatkan oleh lesi yang bersifat non progresif yang terjadi pada saat otak belum matur. Anak dengan kondisi CP memiliki berbagai derajat gangguan kontrol postur yang dapat menyebabkan keterbatasan aktifitas fisik dan partisipasi dalam kehidupan seharihari. Observasi klinis menunjukkan bahwa hippotherapy merupakan strategi yang efektif untuk memperbaiki gangguan kontrol postur pada anak dengan kondisi CP spastik diplegi. Namun, penelitian masih terbatas untuk mendukung hasil tersebut. Studi kasus ini bertujuan untuk melihat pengaruh hippotherapy terhadap kontrol postur pada anak dengan kondisi CP spastik diplegi. Metode: Studi kasus tunggal dengan desain pre dan post test pada anak perempuan dengan kondisi CP spastik diplegi yang berusia 19 tahun. Protokol hippotherapy dilakukan selama 45 menit, dua kali seminggu, selama 3 minggu. Setiap sesi hippotherapy terdiri dari aktifitas stretching, strengthening, dan keseimbangan. Posture assesment scale, adalah sebuah pengukuran dengan teknik observasi berdasarkan kriteria tertentu yang dirancang untuk mengukur perubahan pada kontrol postur anak dengan kondisi CP spastik diplegi, dipilih sebagai alat pemeriksaan. Hasil: Setelah melakukan intervensi selama 3 minggu, terdapat peningkatan skor pada posture assesment scale. Hasil menunjukkan bahwa terdapat perbedaan skor posture assesment scale pada pre hippotherapy $\left(T_{0}=7\right)$ dan post hippotherapy $\left(T_{6}=9\right)$. Kesimpulan: Hasil dari penelitian ini menunjukkan bahwa hippotherapy dapat meningkatkan kontrol postur anak dengan kondisi CP spastik diplegi.
\end{abstract}

Kata kunci: hippotherapy, kontrol postur, cerebral palsy spastik diplegi 


\section{Pendahuluan}

Cerebral palsy (CP) merupakan salah satu gangguan neuromuskular yang paling umum terjadi pada anak-anak. Kondisi ini diakibatkan oleh kerusakan otak yang bersifat permanen dan nonprogresif yang terjadi pada saat prenatal, perinatal, maupun postnatal, yang diikuti oleh gangguan fungsi motorik dan postur [1]. Studi berbasis populasi menyatakan bahwa prevalensi CP berkisar dari 1,5 hingga lebih dari 4 per 1000 kelahiran hidup. Prevalensi CP secara keseluruhan adalah sekitar 2 per 1000 kelahiran hidup [2].

CP memiliki beberapa subtipe klinis. CP yang digunakan dalam studi kasus ini adalah CP spastik diplegi, yaitu $\mathrm{CP}$ yang ditandai dengan spastisitas pada kedua ekstremitas bawah, disertai dengan spastisitas dan inkoordinasi yang lebih ringan pada ekstremitas atas [3]. CP spastik diplegi merupakan tipe $\mathrm{CP}$ yang paling sering terjadi dan berkaitan dengan prematuritas. Periventricular germinal matrix yang merupakan daerah proliferasi neuron yang aktif, sangat rentan terhadap adanya cedera iskemik hipoksia dan perdarahan. Substansia alba yang mengelilinya mengandung serabut saraf pramidal yang turun melalui kapsula interna untuk mempersarafi anggota gerak bawah. Sedangkan pada bagian perifer substansia alba pada periventricular mengandung traktus piramidal dari ekstremitas atas. Oleh karena itu, cedera pada periventricular pada bayi prematur menyebabkan permasalahan yang lebih besar pada ekstremitas bawah daripada ekstremitas atas [4].

Perubahan struktural dan biomekanik pada body alignment serta perubahan sistem muskuloskeletal dapat terjadi pada kondisi CP. Anak dengan kondisi CP spastik diplegi seringkali melakukan mekanisme kompensasi untuk mempertahankan gravitasi dan merekrut grup otot baru untuk mempertahankan stabilitas. Namun, kompensasi jangka panjang menyebabkan muscle imbalance, peningkatan hipertonus, dan deformitas yang memengaruhi kontrol postur. Kontrol postur sangat penting untuk perkembangan keterampilan motorik dan aktivitas fungsional. Oleh karena itu reaksi kontrol postur termasuk straightening, keseimbangan, dan proteksi pada anak CP mengalami delay atau tidak berkembang [5].
Kontrol postur merupakan bagian yang tak terpisahkan dari kemampuan seseorang untuk berinteraksi dengan lingkungan dan terlibat dalam koordinasi gerakan. Anak-anak dengan movement disorder (termasuk cerebral palsy), minimnya kontrol postur yang berkaitan dengan masalah keseimbangan, merupakan faktor pembatas dalam kemampuannya untuk mengikuti kegiatan di sekolah, rumah maupun saat bermain. Penyebab dari tidak adekuatnya kontrol postur ini adalah gangguan pola rekrutmen otot disertai munculnya keterlambatan, sering terjadi koaktivasi pada otot-otot antagonis, dan ketidakmampuan secara adekuat untuk mengintegrasikan permasalahan intersensori [6].

Westcott dan Burtner menyatakan bahwa pemulihan kontrol postur pada anak-anak dengan gangguan keseimbangan harus meliputi kegiatan yang mengarah pada muskuloskeletal, motorik, dan proses sensorik yang menjadi faktor keterbatasan. Penelitian tersebut menyarankan lebih lanjut bahwa intervensi ini harus fokus pada kegiatan keseimbangan baik secara statis dan dinamis selama masa intervensi dan dipraktekkan secara acak sehingga anakanak dapat berpartisipasi aktif. Penelitian yang dilakukan oleh Sherer menunjukkan bahwa hippotherapy merupakan metode yang sesuai dengan persyaratan ini baik secara kemandirian, fungsional, manfaat, dan memotivasi kegiatan yang dilakukan dalam lingkungan nonklinis [6].

Hippotherapy merupakan strategi intervensi yang diberikan fisioterapi dengan menggunakan gerakan multidimensi dari kuda. Hippotherapy telah terbukti dapat meningkatkan keseimbangan, postur, kekuatan otot, range of motion (ROM), dan mengurangi spastisitas. Selain itu, hippotherapy juga dapat meningkatkan koordinasi, kontrol head dan trunk, dan berjalan. Pada hippotherapy, gaya berjalan kuda memberikan pola gerakan yang tepat, smooth, ritmis, dan repetitif pada pasien yang mengendarai kuda yang mirip dengan gerak mekanik jalan pada manusia [7]. Penelitian yang dilakukan oleh Haehl et al telah membuktikan bahwa hippotherapy dapat meningkatkan stabilitas postural. Melalui gerakan kuda yang repetitif dan ritmis, anak dengan $\mathrm{CP}$ spastik diplegi akan mulai mengalami gerakan antisipasi dalam setiap langkah kuda yang berjalan. Anak akan belajar untuk menghasilkan gerakan kompensasi 
yang mengurangi perpindahan pusat gravitasinya dan mempertahankan tubuhnya diatas kuda yang bergerak [5].

Hippotherapy memiliki potensi untuk menjadi intervensi fisioterapi yang efektif terutama untuk meningkatkan kontrol postur yang menjadi penyebab keterbatasan anak dengan kondisi CP spastik diplegi. Namun penelitian masih terbatas untuk membuktikan pernyataan tersebut. Oleh karena itu penulis tertarik untuk meneliti tentang pengaruh hippotherapy terhadap peningkatan kontrol postur anak dengan kondisi $\mathrm{CP}$ spastik diplegi.

\section{Tinjauan Pustaka}

2.1. Cerebral Palsy Spastik Diplegi

Cerebral palsy adalah sekelompok gangguan perkembangan gerak dan postur yang menyebabkan keterbatasan aktivitas yang berhubungan dengan gangguan nonprogresif yang terjadi pada otak janin atau bayi yang sedang berkembang. Anak dengan kondisi CP spastik diplegi memiliki karakteristik seperti peningkatan tonus otot, paresis, kontrol motor involunter, dan permasalahan yang lebih besar pada ekstremitas bawah daripada bagian tubuh yang lain, biasanya memiliki kesulitan dalam mempertahankan keseimbangan karena kontrol postur yang buruk [8].

2.2. Metode dan Teknik Intervensi

2.2.1 Hippotherapy

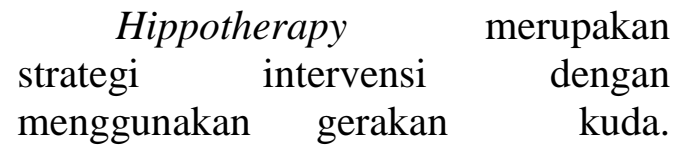

Hippotherapy telah digunakan oleh terapis di Eropa sejak tahun 1960-an untuk meningkatkan kekuatan, keseimbangan, postur, dan fungsi [9].

Alasan digunakannya metode hippotherapy adalah bahwa gerakan tiga dimensi kuda meniru gerakan panggul manusia. Hippotherapy digunakan untuk memecahkan masalah pada anak-anak dengan cerebral palsy yang memiliki gangguan postur, keseimbangan, mobilitas, dan fungsional karena tonus otot yang abnormal [10].

Tujuan utama hippotherapy adalah sebagai berikut: (1) mobilisasi panggul, lumbal, dan hip joint, (2) normalisasi tonus otot, (3) perkembangan kontrol postural kepala dan trunk, dan (4) pengembangan reaksi equilibrium pada trunk [11].
Penelitian menunjukkan bahwa gerakan 3 dimensi pada kuda yang berjalan secara pasif menggerakkan pelvic pada anak dengan gerakan yang sama seperti gerakan yang diperlukan untuk berjalan, sehingga menghasilkan pengaruh ke pusat gravitasi anak pada bidang sagital, frontal, dan transversal. Tidak hanya pada reaksi terhadap gangguan pelvic yang menjadi kebutuhan anak, tetapi juga gerakan maju secara simultan dengan berkesempatan untuk merespon berbagai macam dari rangsangan somatosensori, vestibular, dan visual [6]. Hippotherapy memungkinkan terapis untuk bekerja pada peningkatan kinerja intervensi, sementara anak berpartisipasi pada anggapan yang dimiliki mereka seperti suatu kegiatan permainan dan rekreasi [12]

Salah satu tujuan hippotherapy adalah untuk membuat trunk pada anak menjadi reseptif dan responsif terhadap gerakan yang ditransfer oleh kuda. Hippotherapy telah terbukti dapat meningkatkan koordinasi, meningkatkan kontrol kepala dan trunk, dan gaya berjalan. Selain itu, hippotherapy juga digunakan untuk memfasilitasi peningkatan kontraksi otot, stabilitas sendi, serta respons keseimbangan postural pada anakanak dengan kondisi CP spastik diplegi [11].

Untuk memfasilitasi respon postural khusus, terapis dapat menempatkan penderita dalam berbagai posisi pada kuda seperti telungkup, duduk, side lying, dan side sitting. Beberapa banyak kasus, terapis dan pengendara akan naik bersamasama sehingga terapis dapat memfasilitasi gerakan atau respon yang diinginkan sesuai kebutuhan [3]
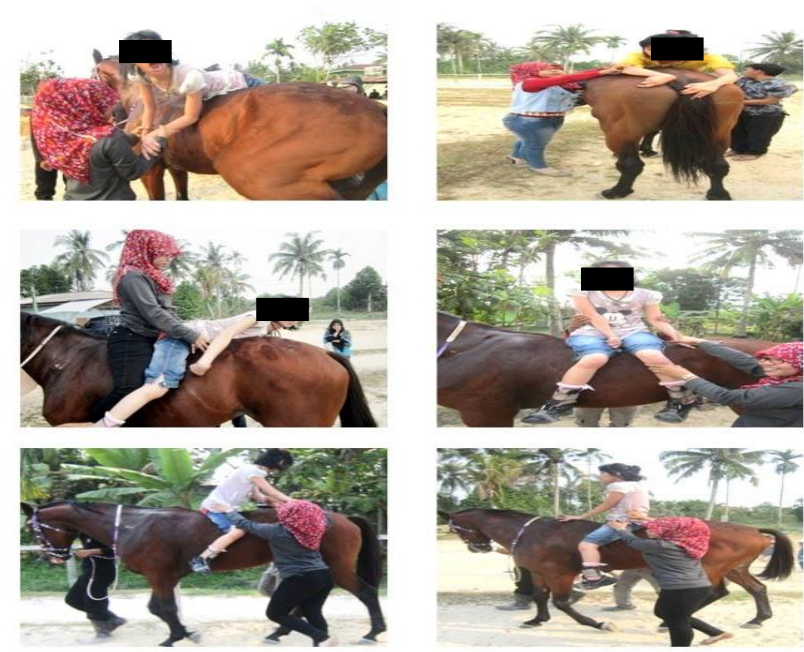

Gambar 1. Contoh berbagai posisi yang digunakan pada hippotherapy 


\subsection{Pemeriksaan dan Pengukuran}

$$
\text { Posture Assesment }
$$

digunakan sebagai alat ukur kontrol postur. Skala ini dapat digunakan untuk melihat perbaikan klinis. Posture Assesment Scale terdiri dari lima item penilaian yang mencakup head dan neck, shoulder dan scapula, trunk, spine, dan pelvic. Masing-masing dari lima item tersebut memiliki variabilitas skor 0-3, dimana 3 adalah skor tertinggi, dan 0 adalah skor terendah.

Posture Assesment Scale dapat digunakan untuk mengukur postur klinis yang diamati dan tes dapat diberikan dengan mudah dan cepat. Karena bisa diberikan cepat, postur dapat dianalisis sebelum keadaan anak-anak lelah dan saat perhatiannya teralihkan [13].

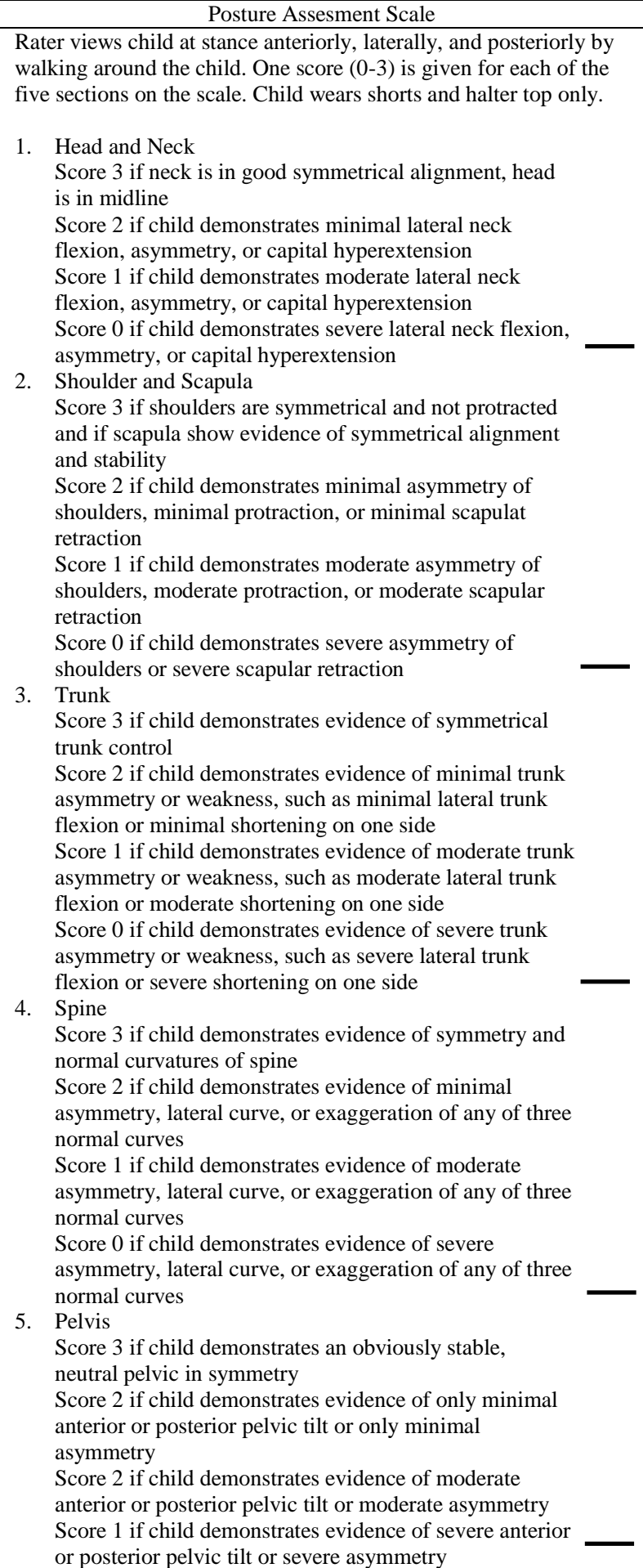
or posterior pelvic tilt or severe asymmetry

Tabel 1. Form Pemeriksaan Posture Assesment Scale

\section{Metode Penelitian}

\subsection{Rancangan Penelitian}

Metode penelitian yang digunakan adalah case study dengan desain penelitian pre dan post test yaitu membandingkan antara skor sebelum dan sesudah intervensi hippotherapy. Case study dilakukan dengan cara meneliti suatu permasalahan melalui suatu kasus yang terdiri dari unit tunggal. Unit tunggal disini berarti satu orang yang terkena satu masalah dan dianalisa secara mendalam baik dari segi yang berhubungan dengan keadaan kasus, faktor penyebab atau yang mempengaruhi, kejadian-kejadian yang muncul sehubungan dengan kasus, maupun tindakan dan reaksi kasus terhadap suatu perlakuan untuk pemaparan tertentu.

\subsection{Subjek}

Kriteria inklusi utama pada case study ini adalah anak yang telah didiagnosis CP spastik diplegi, sudah mampu duduk mandiri tanpa bantuan, mampu berkomunikasi dengan baik, mampu mengikuti arahan, dan mampu melakukan abduksi hip agar mampu duduk diatas kuda. Sedangkan untuk kriteria eksklusi meliputi selective dorsal rhizotomy, kejang, alergi terhadap kuda dan debu, mengalami prosedur bedah dalam 12 bulan sebelum pengujian, gangguan penglihatan, dan retardasi mental sedang hingga berat.

Subjek yang dipilih dalam case study ini adalah anak berjenis kelamin perempuan berusia 19 tahun yang mengalami CP spastik diplegi. Subjek merupakan anak tunggal. Subjek lahir melalui persalinan normal dengan berat 3600 gram dan panjang $54 \mathrm{~cm}$. Ibu subjek juga tidak memiliki gangguan saat kehamilan. Namun saat berusia 9 bulan, subjek menderita demam tinggi dan steps. Subjek mengalami koma selama 7 hari.

Subjek memiliki kesadaran, motivasi, kognitif dan emosi yang cukup baik. Subjek mampu duduk secara mandiri, dan berdiri serta berjalan dengan bantuan. Pemeriksaan pola postural subjek didapat pada bagian stabilitas leher : (1) Kepala dan leher belum stabil, aksis kepala kurang simetris (cenderung sedikit lateral neck fleksi sinistra dan hiperekstensi), (2) aktivitas tendon guard masih meningkat pada leher kiri, (3) stabilisasi proksimal kedua bahu belum stabil, (4) aktivitas 
tendon guard masih meningkat pada kedua lengan. Sedangkan untuk stabilitas proksimal didapat: (1) aksis pelvik masih belum simetris dan belum stabil, pelvic lebih pada posisi tilting ke posterior, (2) kedua tungkai sudah mampu menumpu dengan bidang tumpu yang lebar, (3) tumpuan kaki belum cukup kuat dan ankle dalam posisi inversi, dan (4) keseimbangan berdiri masih kurang baik.

Setelah subjek dan orangtua subjek diberikan penjelasan tentang tujuan serta maksud dari penelitian tersebut, subjek diminta menandatangani lembar persetujuan menjadi sampel sebagai bentuk informed consent untuk menjadi sampel penelitian. Kemudian diminta persetujuannya melalui orang tua sampel untuk dijadikan sampel penelitian ini. Evaluasi diberikan pada saat sebelum pelaksanaan terapi dan setelah pelaksanaan terapi dengan pemberian intervensi sebanyak 6 kali terapi.

\subsection{Tempat dan Waktu}

Penelitian dilakukan di Klinik Special Kids Pekanbaru. Penelitian dilakukan mulai Januari sampai dengan Maret 2014.

\subsection{Pelaksanaan Intervensi}

Dosis latihan menggunakan metode Hippotherapy dilakukan dengan frekuensi latihan sebanyak enam kali (6x) terapi dengan jadwal terapi dua kali (2x) per minggu, durasi latihan selama 45 menit, dengan latihan fokus kepada kontrol postur, kontraksi trunk, postural alignment, dan penguatan ekstremitas atas dan bawah yang dilakukan selama kurang lebih 30 menit. Sisa waktu sesi sekitar 10 menit dilakukan berdasarkan terapi latihan seperti stretching dan 5 menit untuk setup setiap sesi, meliputi posisi telungkup (telungkup menghadap satu sisi dan menghadap ekor kuda), duduk (duduk menghadap ekor kuda dan menghadap kedepan), dan side sitting.

\section{Hasil dan Pembahasan}

\subsection{Hasil}

Hasil penelitian pelaksanaan hippotherapy yang telah dilakukan selama 3 minggu didapatkan hasil pada sampel penelitian:

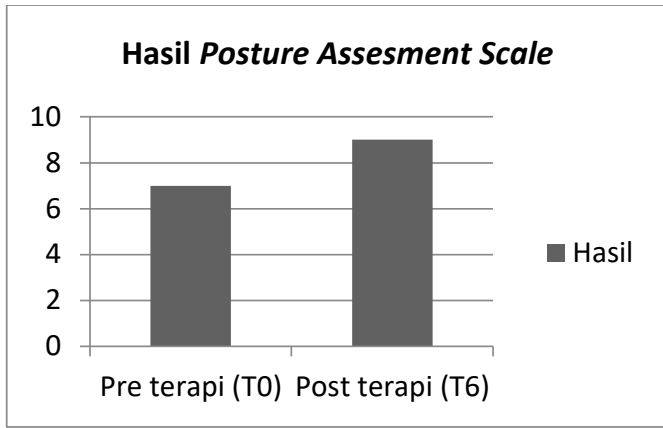

Gambar 2. Hasil Evaluasi Posture Assesment Scale

Dari hasil evaluasi pengukuran pemeriksaan postur dengan menggunakan Posture Assesment Scale ditemukan hasil Posture Assesment Scale dengan skor 7 pada evalusi pertama (T0) dan 9 pada evaluasi akhir (T6), sehingga ditemukan adanya selisih sebanyak 2 skor terhadap peningkatan postur anak.

\subsection{Pembahasan}

Hasil yang diperoleh dari penelitian dengan metode hippotherapy dapat memberikan hasil yang baik terhadap peningkatan kontrol postur, walaupun upaya untuk meningkatkan kontrol postur sebenarnya membutuhkan waktu yang lama. Frekuensi latihan diberikan 2 kali dalam seminggu dengan durasi 45 menit tentu belum mempunyai pengaruh secara progresif terhadap kemampuan kontrol postur subjek melalui metode hippotherapy.

Dari hasil evaluasi pengukuran dengan menggunakan Posture Assesment Scale, di temukan hasil skor 7 pada evaluasi pertama (T0) dan 9 pada evalusi akhir (T6), dapat disimpulkan terjadi peningkatan 2 skor terhadap peningkatan kontrol postur anak.

Hal tersebut juga diungkapkan melalui penelitian oleh Strauß. Penelitian tersebut menunjukkan bahwa berjalan dengan kuda menyebabkan terdapatnya 90-120 gerakan impuls per menit pada trunk, yang menyebabkan gerakan up down, forwards backwards, side to side, rotasi, dan fleksi lateral pada lumbal. Hippotherapy dapat memecahkan permasalahan pada anak cerebral palsy melalui kesempatan belajar motorik yang unik dengan memanfaatkan gerakan kuda. Bersamaan dengan fasilitasi kontrol trunk dalam pola gait yang khas, hippotherapy juga akan menyebabkan munculnya regulasi tonus otot, efek tersebut juga dilaporkan oleh semua studi penelitian. Sehingga terjadi 
penghambatan pola gerakan yang abnormal. Hippotherapy menyebabkan anak untuk dapat menyeimbangkan trunk diatas pergerakan base of support yang lebih kompleks, sebuah pengalaman yang biasanya tidak didapat, dan dengan demikian memberikan anak dengan kondisi $\mathrm{CP}$ spastik diplegi memiliki kesempatan untuk belajar motorik. Beberapa anak dengan kondisi $\mathrm{CP}$ juga mengalami peningkatan kemampuan berdiri dan berjalan setelah melakukan hippotherapy. Hal ini konsisten dengan efek hippotherapy didokumentasikan dalam literatur yang ada. [14]

Selain itu penelitian oleh Debuse juga menunjukkan bahwa efek utama dari hippotherapy yaitu adanya normalisasi tonus otot, meningkatkan kontrol trunk, meningkatkan kemampuan berjalan, sehingga memberi pengaruh pada perbaikan aktivitas sehari-hari dan meningkatkan kemandirian pasien. Saat hippotherapy dilakukan maka secara otomatis akan terjadi perbaikan pada impairment, aktifitas, partisipasi dan kualitas hidup anak dengan kondisi CP spastik diplegi. [15]

\section{Kesimpulan}

Berdasarkan hasil penelitian dan pembahasan di atas maka kesimpulan yang dapat di ambil adalah bahwa pemberian hippotherapy dapat meningkatkan kontrol postur pada anak cerebral palsy spastik diplegi.

\section{REFERENSI}

[1] F. Veronika, K. Eva, S. Zdeněk, E. Milan, and J. Miroslav, "The effect of hippotherapy on gait in patients with spastic cerebral palsy," Acta Gymnica, vol. 43, no. 4, pp. 17-23, 2013.

[2] O. Erez, "Cerebral Palsy - Trends in epidemiology and Recent Development in Prenatal Mechanisms of Disease, Treatment, and Prevention," vol. 5, no. 21, pp. 1-10, 2017.

[3] T. Shurtleff and J. Engsberg, "Longterm effects of hippotherapy on one child with cerebral palsy: a research case study," vol. 75 , no. 8, pp. 359366, 2016.

[4] M. M. Jan, "Cerebral Palsy:
Comprehensive Review and Update," vol. 26, no. 2, pp. 123-132, 2014.

[5] A. G. Moraes, F. Copetti, V. R. Angelo, L. L. Chiavoloni, and A. C. David, "The effects of hippotherapy on postural balance and functional ability in children with cerebral palsy," vol. 28, no. 8, pp. 2220-2226, 2016.

[6] D. J. Silkwood-sherer et al., "Research Report Hippotherapy An Intervention to Habilitate Balance Deficits in Children With Movement Disorders : A Clinical Trial," vol. 92, no. 5, pp. 707-717, 2012.

[7] M. C. Mcgee and N. B. Reese, "Immediate Effects of a Hippotherapy Session on Gait Parameters in Children with Spastic Cerebral Palsy," Pediatr. Phys. Ther., pp. 212218, 2009.

[8] Y.-H. Ju, I.-S. Hwang, and R.-J. Cherng, "Postural Adjustment of Children With Spastic Diplegic Cerebral Palsy During Seated Hand Reaching in," Arch Phys Med Rehabil, vol. 93, pp. 471-479, 2012.

[9] R. L. Casady and D. S. Nicholslarsen, "The Effect of Hippotherapy on Ten Children with Cerebral Palsy," 2004.

[10] J. Kwon, H. J. Chang, J. Y. Lee, and Y. Ha, "Effects of Hippotherapy on Gait Parameters in Children With Bilateral Spastic Cerebral Palsy," Arch Phys Med Rehabil, vol. 92, pp. 774-779, 2011.

[11] M. Zadnikar and A. Kastrin, "Effects of hippotherapy and therapeutic horseback riding on postural control or balance in children with cerebral palsy: a meta-analysis," Dev. Med. Child Neurol., vol. 53, pp. 684-691, 2011.

[12] A. Frank, S. Mccloskey, and R. L. Dole, Effect of Hippotherapy on Perceived Self-competence and Participation in a Child With. 2011, pp. 301-308.

[13] R. Saether, "Clinical tools to assess balance in children and adults with cerebral palsy: a systematic review," Dev. Med. Child Neurol., vol. 55, pp. 988-999, 2013.

[14] I. Strauß, Hippotherapie- 
Physiotherapie mit und aufdem Pferd. Stuttgart: Thieme, 2007.

[15] D. Debuse, Effects of hippotherapy on people with cerebral palsy from the useers perspective. London: Informa Healthcare, 2009.

Sari Triyulianti, memperoleh gelar Sarjana Fisioterapi di Universitas Esa Unggul pada tahun 2017 dan pada tahun 2020 telah menyelesaikan program Magister Ilmu Biomedik di Universitas Indonesia. Saat ini sebagai Dosen Tetap Prodi D-III Fisioterapi Universitas Abdurrab. 